\title{
OCORRÊNCIA DE DOENÇAS DO PAK CHOI NO ESTADO DO PARANÁ, BRASIL
}

\author{
${ }^{1}$ MARISTELLA DALLA PRIA, ${ }^{2}$ MARISE C. MARTINS, ${ }^{1}$ MARIE Y. REGHIN \& ${ }^{1}$ GERLIANE L. MAIA
}

${ }^{1}$ Departamento de Fitotecnia e Fitossanidade, Universidade Estadual de Ponta Grossa, Praça Santos Andrade s/n, CEP 84010-790, Ponta Grossa, PR, fax: (042) 220-3072, e-mail: mdallapria@uepg.br; ${ }^{2}$ Departamento de Entomologia, Fitopatologia e Zoologia Agrícola, Escola Superior de agricultura "Luiz de Queiroz", Cx. Postal 09, CEP 13418-900, Piracicaba, SP

(Aceito para publicação em 15/03/2002)

Autor para correspondência: Maristella Dalla Pria

DALlA PRIA, M., MARTINS, M.C., REGHIN, M.Y. \& MAIA, G.L. Ocorrência de doenças do pak choi no estado do Paraná, Brasil. Fitopatologia Brasileira 27:316-318.2002.

\section{RESUMO}

A cultura do pak choi (Brassica chinensis), hortaliça de origem Asiática, foi introduzida no Brasil há dois anos por empresas importadoras de sementes. No estado do Paraná vem se destacando na região de Curitiba, principalmente em condições de cultivo protegido. Realizou-se um levantamento da ocorrência de doenças na cultura na safra 1999/2000. Os experimentos foram conduzidos na Fazenda Escola "Capão da Onça" da Universidade Estadual de Ponta Grossa (UEPG), com a diagnose das doenças sendo realizada nos laboratórios de fitopatologia da UEPG e da ESALQ/USP. As doenças que apresentaram maior intensidade na safra de verão foram a Mancha de Alternaria (Alternaria sp.), a Podridão Mole (Erwinia sp.) e a Ferrugem Branca (Albugo candida). Na safra de outono, a Mancha de Alternaria e a Podridão Mole apresentaram baixa incidência e não se observou a ocorrência de Ferrugem Branca.

Palavras-chave adicionais: Brassica chinensis, Alternaria sp., Erwinia sp., Albugo candida.

\section{ABSTRACT \\ Occurence of pak choi diseases in the State of Parana, Brazil}

Pak choi (Brassica chinensis) is a vegetable crop that was recently introduced in Brazil from Asia by seed importer companies. In the state of Parana this crop is becoming increasingly important in the Curitiba area, mainly under protected cultivation. A survey of diseases in this crop was performed during the growing period of 1999/2000, in the School Farm "Capão da Onça" of the Ponta Grossa
State University. Materials collected were analyzed at the plant pathology laboratories of this university and at the University of São Paulo, at Piracicaba. In the summer crop, the most prevalent diseases were: Alternaria spot (Alternaria sp.), soft rot (Erwinia sp.) and white rust (Albugo candida). In the fall, there was a low incidence of Alternaria spot and soft rot and white rust did not occur at all.
O pak choi (Brassica chinensis L.) é uma hortaliça de origem Asiática (Hill, 1990) que foi introduzida no Brasil há dois anos por empresas importadoras de sementes. No Estado do Paraná vem-se destacando na região de Curitiba, principalmente em condições de cultivo protegido.

A planta é parecida com acelga [Brassica chinensis (L.) Czern], apresentando as folhas lisas, oblongas e com pecíolos brancos e carnosos (Maroto, 1995), atingindo de 30 a $40 \mathrm{~cm}$ de altura. Esta hortaliça é usada na dieta alimentar por ser rica em vitaminas e sais minerais, podendo ser consumida crua, na forma de salada, ou cozida.

Com relação às condições climáticas favoráveis ao seu cultivo, observações a campo mostram que temperaturas amenas são favoráveis para o desenvolvimento vegetativo; sendo a duração do ciclo variável em função da temperatura. De um modo geral, o ciclo é rápido, em torno de 70 a 80 dias da semeadura. O desenvolvimento vegetativo pode ser interrompido se ocorrer a emissão da haste floral, o que é altamente indesejável para o produtor. Isto parece ser decorrente não só de temperaturas baixas, mas também de fotoperíodo longo. Com relação à ocorrência de doenças, poucos são os dados existentes na literatura (Maroto, 1995; Stobbs et al., 1998).

Este trabalho teve por objetivo relatar pela primeira vez a ocorrência de doenças no pak choi, em condições brasileiras, especificamente na região de Ponta Grossa, PR.

O levantamento das doenças foi realizado nas safras 1999 e 2000, em dois ciclos da cultura, nos híbridos Canton e Chouyou, comercializados pela Agroflora/Sakata e pela Sakama, respectivamente.

Os experimentos foram conduzidos na Fazenda Escola "Capão da Onça" da Universidade Estadual de Ponta Grossa. A análise do material infetado e a diagnose das doenças foram realizadas nos laboratórios de fitopatolologia da UEPG e da ESALQ/USP.

A semeadura foi realizada em substrato Plantmax em bandejas de poliestireno expandido e o transplantio para o campo foi realizado quando as mudas apresentavam quatro a seis folhas definitivas. $O$ espaçamento utilizado foi de 0,25 x $0,25 \mathrm{~m}$, com 36 a 40 plantas por parcela. As avaliações da 
ocorrência de doenças foram efetuadas durante o desenvolvimento vegetativo e no momento da colheita. Plantas com suspeita de doenças foram coletadas e levadas aos laboratórios de fitopatologia para determinação da etiologia e comprovação da patogenicidade.

Os dois híbridos tiveram comportamento semelhante em relação à suscetibilidade às doenças detectadas (Tabela 1)

Os sintomas de Mancha de Alternaria (Alternaria sp.) ocorreram em plantas adultas, iniciando-se pelas folhas mais externas. As lesões eram inicialmente pequenas e necróticas e, com seu desenvolvimento, tornaram-se circulares, concêntricas e em alguns casos com halo amarelo (Figura 1A).

$\mathrm{O}$ isolamento de fungo do gênero Alternaria foi realizado a partir de lesões nas folhas, retirando-se fragmentos de cerca de $3 \mathrm{~mm}$ da região limítrofe entre o tecido doente e o tecido sadio. Os fragmentos foram desinfestados em hipoclorito de sódio $0,5 \%$, por 2 a 3 min e então plaqueados em placas de Petri contendo meio batatadextrose-ágar (BDA) e incubados a $22{ }^{\circ} \mathrm{C}$. Foram obtidos dois isolados deste fungo.

A partir das culturas puras obtidas, procedeu-se a inoculação de plantas com 45 dias de idade, transplantadas em vasos contendo solo estéril, pulverizando-se suspensão de conídios na concentração de $1,5 \times 10^{5}$ esporos $/ \mathrm{ml}$, acrescido de Tween (uma gota para cada $100 \mathrm{ml}$ ) em ambas as faces da folha. Foram incubadas quatro plantas do híbrido Choyou, para cada isolado. Como testemunha pulverizouse água destilada esterilizada. Os dois isolados de Alternaria mostraram-se patogênicos, de acordo com observações realizadas diariamente, durante 15 dias, após a inoculação.

A Podridão Mole, causada pela bactéria Erwinia sp., manifestou-se em plantas bem desenvolvidas, inicialmente como murcha. Os tecidos da base das folhas tornaram-se encharcados, seguidos de podridão (Figura 1B), muitas vezes apresentando odor fétido. A arquitetura das plantas propicia o acúmulo de água na base das folhas, favorecendo o desenvolvimento do patógeno. $\mathrm{O}$ isolamento da bactéria foi realizado conforme a metodologia de Takatsu et al. (1981).

As lesões de Ferrugem Branca, causada por Albugo candida (Pers.) Kuntze (Figura 1C), surgiram na fase inferior das folhas, com pústulas brancas de aspecto pulverulento. $\mathrm{Na}$ face superior das folhas apresentaram amarelecimento e pequenas distorções.

$\mathrm{Na}$ safra de verão as doenças que se manifestaram em maior intensidade foram a Mancha de Alternaria, a

TABELA 1 - Doenças detectadas em plantas de Pak choi (Brassica chinensis) no campo experimental da Fazenda Escola "Capão da Onça", Universidade Estadual de Ponta Grossa, PR, nas safras 1999 e 2000

\begin{tabular}{lc}
\hline \hline Doença & Patógeno \\
\hline Mancha de Alternaria & Alternaria $\mathrm{sp}$. \\
Podridão Mole & Erwinia $\mathrm{sp}$. \\
Ferrugem Branca & Albugo candida \\
\hline
\end{tabular}

Podridão Mole e a Ferrugem e na safra de outono, a Mancha de Alternaria e a Podridão Mole apresentaram baixa incidência, não se observando a ocorrência de Ferrugem Branca.
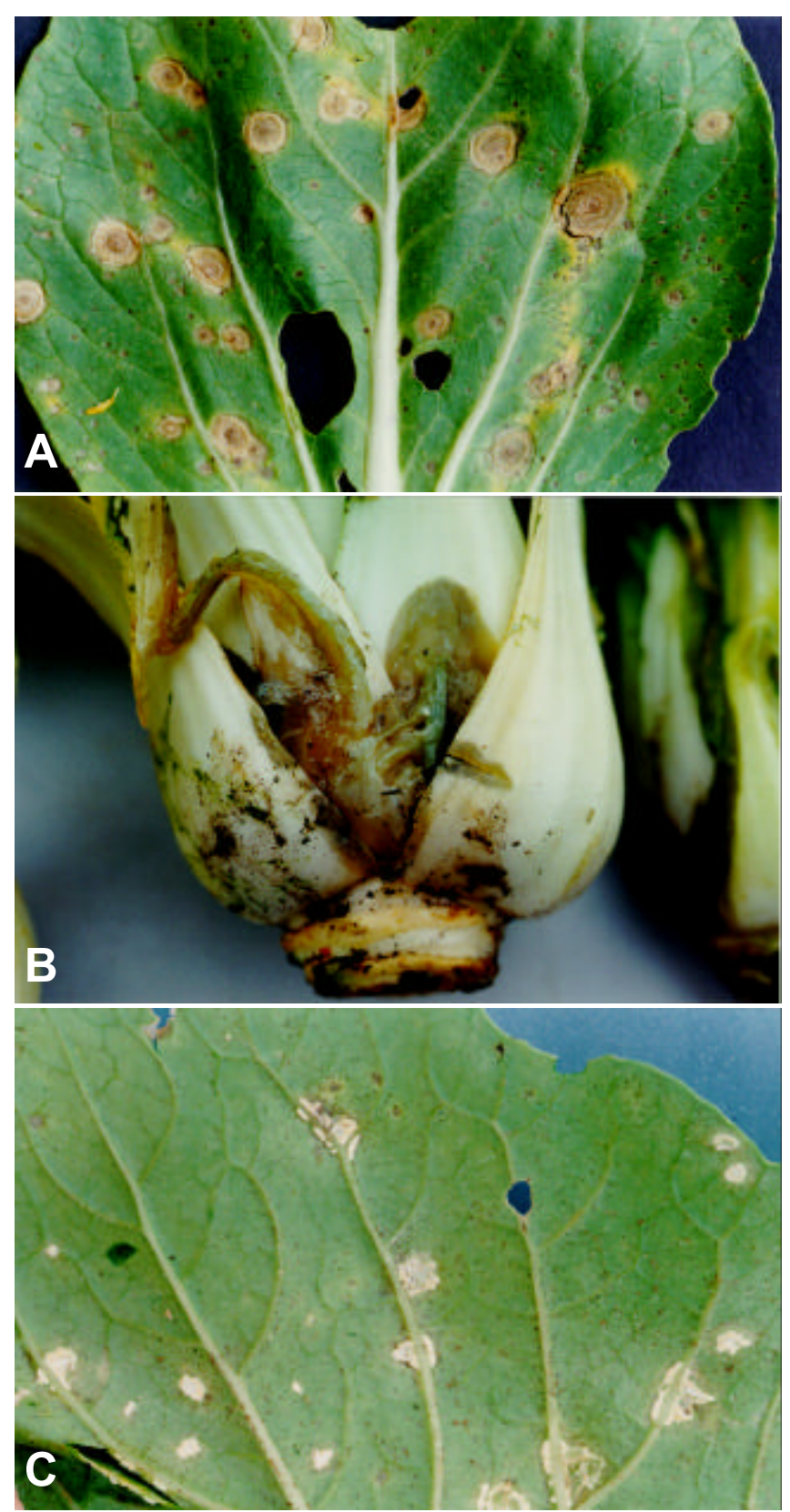

FIG. 1 - Sintomas de Mancha de Alternaria (A), Podridão Mole (B), e Ferrugem Branca (C) em plantas de pak choi (Brassica chinensis).

\section{REFERÊNCIAS BIBLIOGRÁFICAS}

HILL, D.E. Chinese cabbage and Pak choi trials 1988-1989. Connecticut Agricultural Experiment Station, New Haven. 870. 1990.

MAROTO, J.D. Horticultural Herbacea Especial. $4^{\mathrm{a}}$ ed. Madrid. Edicones Mundi-prensa. 1995. 
M.D. Pria et al.

TAKATSU, A., MELLO, S.C.M. \& GARCIA, E.S.O.B. Fruto de pimentão como meio parcialmente seletivo para isolamento de Erwinia carotovora. Fitopatologia Brasileira 6:551. 1981. (Resumo).
STOBBS, L.W., CERKAUSKAS, R.F., LOWERY, T. \& DRIEL, L. VAN. Occurence of turnip yellow mosaic virus on oriental cruciferous vegetables in southern Ontario, Canada. Plant Disease 82:351. 1998. (Note). 